\title{
Identificación y descripción de la intimidación escolar en instituciones educativas del municipio de Popayán*
}

\author{
Identification and description of school bullying \\ in institutions in the municipality of Popayan
}

\author{
Óscar A. Erazo Santander* \\ Fundación Universitaria de Popayán, \\ Colombia \\ Recibido: 20 de septiembre de 2015 \\ Revisado: 30 de octubre de 2015 \\ Aceptado: 12 de enero de 2016
}

\section{Resumen}

Se identifica y describe el fenomeno de la intimidación escolar en una muestra de 1.300 estudiantes, 513 padres y 81 docentes de 5 instituciones educativas del municipio de Popayán, Colombia. Se utilizó metodología cuantitativa-descriptiva y análisis con SPSS en frecuencias relativas. Los resultados demuestran la existencia de intimidación física en el $44 \%$ a través de golpes, patadas y quitar elementos escolares, e intimidación psicológica en el $70 \%$ incluyendo gritar a un compañero, poner apodos, coaccionar, amenazar y excluir. En el $35.1 \%$ los profesores consideran el problema como grave en su institución, y que es necesaria su reflexión en el $71.6 \%$, el $31.4 \%$ de los padres consideran muy grave el problema.

Palabras clave: intimidación escolar, intimidación fisica y psicológica. 


\section{Abstract}

he goal was to describe school bullying is identified and described in a sample of 1300 students, 513 parents and 81 teachers from five schools in Popayán, Colombia. We used quantitative methodology to describe and analyze in terms of relative frequencies with SPSS. Results show a 44\% prevalence of school bullying, through punches, kicks, theft of school materials, and psychological intimidation in $70 \%$, including yelling at peers, name-calling, coercion, threats and exclusion. $35.1 \%$ of the teachers and $31.4 \%$ of the parents regard the situation as significant, and $71.6 \%$ consider that a reflection on the subject is needed.

Keywords: brain activity, attention, alcohol, BCI (Brain Control Interface).

\section{Introducción}

Considerar a la escuela un sitio sagrado y alejado de los problemas cotidianos es una utopía, y como cualquier espacio social tiene múltiples dificultades (Boggon, 2006; Erazo, 2013), uno de ellos es la violencia, concebido como el "acto de agresión (...) contra una persona, (...), en condiciones de aparente o real superioridad por móviles económicos, políticos, sociales, ideológicos, culturales y pudiendo tener como consecuencia extrema la muerte" (Camargo, 1996, p. 89), su proyección en la escuela se denomina intimidación escolar y existe desde el preescolar hasta la universidad, y también se ve en instituciones oficiales, privadas y a nivel urbano o rural (Erazo, 2012; Ortega y Monks, 2005; Defensor del Pueblo, 2007; Zubiría, 2006).

Su designación en España al igual que en Estados Unidos es bullying, (Defensor del Pueblo, 2007; Green, 2007; Pautasso, 2006) en Latinoamerica es matonaje, en Chile (Barria, Matus, Yañez y Mora, 2004) patoterismo, en Argentina (Torres, 2005) y en Colombia es abuso, acoso (Paredes, Álvarez, Lega y Vernon, 2008), violencia escolar o intimidacion (Chaux, 2003), pero al final todos incluyen rasgos de agresión, de ahí que Aviles (2009) lo describa como,
La forma repetida y mantenida en el tiempo, siempre lejos de la mirada de los adultos y teniendo la intención de humillar y someter abusivamente a una víctima indefensa por parte de un abusón o grupo de matones a través de agresiones físicas, verbales y sociales con resultados de victimización psicológica y rechazo grupal (p. 86).

Su conceptualización inició en Noruega con Dan Olweus (1998) en la década de los 80 , más adelante Bergen (2007, citado en Bustillo, 2014), denunciaría que el $15 \%$ de estudiantes de secundaria estaban implicados en el fenómeno, y para el 2001 la cifra era del 59 \%. Smith (2000, citado en Serrano e Iborra, 2005) en Inglaterra describía la existencia del fenómeno en el $19 \%$ de estudiantes entre los 12 y 16 años. En Italia, (Menesinni et al. 1996, citado en Torres, Orejudo, Nasarre, Lanuza, Madonar y Moreno, 2006) lo describían en $30 \%$, pero en el 2001 referenciaban el $40 \%$. Francia en 1993 (citado en Torres y colaboradores, 2006) a través del Ministerio del Interior realizaría el primer censo sobre violencia escolar, identificando 771 agresiones contra escolares y 210 contra profesores, pero en 1999 nombraba 240.000 incidentes de los cuales el $3 \%$ eran muy graves. En España, el Defensor del Pueblo (2007) describía 
que al $33.8 \%$ de escolares los insultan, al $8.5 \%$ los amenazan, al $6.4 \%$ los roban, al $4.1 \%$ los golpean, al $1.7 \%$ los acosan sexualmente, al $0.7 \%$ los obligaban a hacer conductas inapropiadas y a un 0.6 $\%$ lo amenazan con armas. Ortega y Monks (2005), identifican el fenómeno en estudiantes de preescolar y para inicios del siglo XXI, Aviles (2010) nombraba la existencia del ciberbullying.

En Estados Unidos, Green (2007), en una muestra de 8.478 estudiantes de 8 instituciones de secundaria en Nueva York, encontró que el $16 \%$ eran víctimas, de estos el $47 \%$ son chicos y el $53 \%$ chicas, en que el $90 \%$ presentaban dificultades afectivas y un $10 \%$ terminaba en el hospital por palizas recibidas. En América Latina, Galvez-Sobral (2011) en Guatemala explica la existencia de un $21 \%$ de víctimas siendo de alta vulnerabilidad los chicos de 14 años, en el que 7 de 100 son excluidos y 5 de 100 agredidos físicamente, en Chile, Mertz (2006), nombra que el $14 \%$ de los encuestados perciben la existencia de la violencia en las escuela, el $17 \%$ es agredido físicamente y el $48 \%$ es insultado o agredido verbalmente, y Tamar (2005) denuncia que el fenómeno no es solo entre estudiantes, también entre docentes y estudiantes. Barría y colaboradores (2004), en Temuco (Chile), nombra una relación positiva entre el rendimiento académico y la intimidación.

En Argentina, Pautasso (2006) y Ventura (2006), nombran que el $46 \%$ de los estudiantes son maltratados psicológicamente y a un $24 \%$ los golpean. En Colombia, Llorente, Chaux y Salas (2005) concluyen que el estudiante intimidador presenta rasgos de trastornos de la conducta, personalidad con un patrón de inestabilidad conductual, afectiva y social. Cepeda, Pacheco, García y Piraquive (2008), nombran que en Bogotá un 38 \% de estudiantes es agredido psicológicamente y ha sido robado (Camacho y Ramos de Sánchez, 2003) y en donde las víctimas desertan de la escuela como consecuencia de las amenazas recibidas (Álvarez y Rueda, 2013). En Cali, Paredes (2006) encontró que el $44 \%$ de los estudiantes ha sido alguna vez ridiculizado, excluido y amenazado con instrumentos escolares o golpeado, y un $11 \%$ se reconoce como agresor. En el Cauca, Rodríguez y Celada (2005) describen que el $28 \%$ de estudiantes son agredidos, y Erazo (2015) ha venido reportando la existencia de problemas de conducta entre estudiantes en casi el $42 \%$.

El fenómeno en ocasiones ha dejado de considerarse un juego y se ha iniciado el reporte de hechos escolares que incluyen aspectos aberrantes como los nombrados por la prensa Alemana en el 2004 (citado en Bustillo, 2014), con el comportamiento de 11 estudiantes que obligaban a sus víctimas a ingerir tiza, comerse los filtros de cigarrillos y realizar actos humillantes (sexual) en público, incluían golpes con barras y destornilladores, hechos que fueron presentados ante estamentos judiciales e implicando penas de 6 años para los agresores que eran estudiantes entre 16 y 18 años, o como en Bogotá (Colombia,), en donde 30 estudiantes reportaban la necesidad de desertar de las escuelas como única forma de terminar con las continuas amenazas que les hacían (Prensa 2010, citado en Álvarez y Rueda, 2013), y donde se ha demostrado que existe desconocimiento del tema por parte de los docentes y comunidad educativa y sus formas de control e intervención son en la gran mayoría equivocadas (Erazo, 2012; Vázquez, Sarramona y Touriñan, 2009).

\section{Actores de la intimidación escolar}

En el fenómeno participan el agresor, la víctima y el observador. El agresor, inicia la intimidación a través de múltiples acciones de maltrato, además las regula en intensidad, frecuencia y tiempo (puede durar días o años), (Sutton y Keogh 2000, citado en Aviles, 2009; Olweus 1998, citado en Pautasso, 2006). García (1997) lo describe así:

Paco es un muchacho de 13 años alto y fuerte, va andando por los pasillos de la escuela con sus amigos José y Pedro. La clase de matemáticas ha sido aburrida y Paco necesita algo de actividad. Entre montones de cabezas distingue una que viene en sentido contrario, es Luis, un chico de 12 años al que conoce del autobús. Paco se desvía ligeramente de su camino interponiéndose en el de Luis. Cuando este que va algo distraído llega a su altura, recibe un coscorrón poco amistoso en la cabeza. Luis se duele, levanta la cabeza y su cara 
refleja una mezcla de terror y de sorpresa. Paco por el contrario lo mira desafiadoramente, con aire de superioridad le sonríe y repite el coscorrón antes de alejarse en dirección al patio. Luis que no ha proferido una sola palabra durante todo el suceso, permanece cabizbajo doliéndose en el mismo lugar de los hechos (p. 52).

La funcionalidad del agresor es considerada desde la psicología cognitiva como una motivación organizada por sus estructuras mentales, uno de sus exponentes es García (1997), quien cree que el agresor tiene estructurado un modelo mental que lo lleva a procesar, interpretar y responder la información ambiental de manera agresiva y violenta (Laird 1983, citado en García, 1997), la estructura se formaría, "desde fases muy tempranas (...) con activación de memorias a largo plazo y el uso de repuestas operativas ante las diferentes situaciones de cotidianidad" (p. 57).

Este modelo es dinámico e integra diversas conceptualizaciones entre personajes, situaciones, hechos y experiencias, guiando su procedimiento de memoria, acción y operación en un modelo mental que opera en una matriz de primitivos, representada en espacio, tiempo, personas, objetos y vínculos como causa, intención y meta. Esta representación no constituye una copia de la situación, sino que es la construcción del sujeto, regulando la estimulación, los medios, objetivos y condiciones internas y ambientales, un ejemplo de este proceso es expuesto por García (1997) así:

El agresor distingue la cabeza de la víctima entre las del resto, su modelo mental se modifica. A partir de lo percibido recupera de su memoria a largo plazo la información sobre la víctima, es un sujeto débil al que ha atosigado en muchas ocasiones, está categorizado como víctima propiciatoria (...) y en donde el medio oferta la posibilidad de disfrutar de algo de diversión a costa de otro (meta) operando una secuencia de medios (meta), como acercarme a la víctima, sujeto débil, ponerme en su camino y darle un coscorrón (medios), disfrutando de mi superioridad y su insignificancia (meta) (p. 85).
Otro ponente de la propuesta cognitiva es Díaz (2004), quien ha nombrado la existencia de sesgos cognitivos, pensamientos distorsionados y estructuras mentales, y que clasifica en, a) visión de túnel, consiste en recuerdos y pensamientos de situaciones negativas o percepción de dolor vividas $u$ observadas que hacen interpretaciones radicales de personas, relaciones o formas de resolver conflicto. Estas estructuras no permiten la integración de nueva información, así la nueva experiencia sea diferente a la del esquema irracional. Ejemplo, la discriminación por raza, rasgos físicos o generalización de venganza; b) absolutismo y pensamiento dicotómico, tendencia a percibir la realidad en blanco o negro llevando a la sobregeneralización o exageración de una realidad, y utilizándose términos absolutos (todos, nadie, siempre, nunca), ejemplo, solo si golpeas te respetan o solo a las malas se solucionan los problemas; c) fatalismo, percepción de falta de control sobre los acontecimientos y en donde se requiere el uso de la violencia o el maltrato como forma de protección, ejemplo, golpes a la mujer por celos; d) confusión de pensamientos y emociones, estructura mental en la que el agresor considera que su forma de comportamiento es adecuada y aceptada por el medio y no puede reconocer dolor o sufrimiento en otros, ejemplo, el agresor considera que su objeto de burlas también las disfruta y que todo el curso lo disfruta; e) interpretación exagerada de la conducta de los demás y las considera peligrosas, lleva a actuar preventivamente.

Estos sesgos atribucionales también son descritos por Aviles (2009) y Díaz (2004), y Paredes (2008) considera que son peligrosos, ya que justifican la acción del intimidador y tergiversa su pensamiento moral identificando al agresor como un estudiante desensibilizado por la conducta cruel y la falta de vergüenza, preocupación o culpabilidad, incluso podrían sentirse satisfechos por su acción.

Ruiz, Llor, Puebla y Llor (2009), consideran que la acción esconde intencionalidades centradas en cuatro actitudes. 1) factor de autoestima, se realiza la acción para obtener refuerzo social; 2) diversión, se intimida para reírse y producir jocosidad y risas, 3) resolución de conflictos, se utiliza la 
violencia como forma de solucionar problemas, y 4) forma de defensa y justicia, como la venganza.

De forma más compleja, Cerezo (1998) ha encontrado dos tipos de agresores, 1) el que se caracteriza por un bajo nivel de autoestima y autoconcepto, buscando de manera desesperada la oportunidad de aprobación, realizando actos de dominación a otros que considera inferiores y obteniendo refuerzos de personas que lo reconocen como el bravucón (Kusel y Perry 1988, citado en García, 1997), son depresivos, con tendencia suicida (Díaz, 2004), y tienen labilidad emocional; 2) es líder con alta autoestima, pero con características de psicoticismo, extraversión y neuroticismo (Cerezo, 1998; Genes y Georgen citado en Díaz, 2004), es impulsivo con baja tolerancia a la frustración, necesidad de dominio, baja empatía hacia el sufrimiento y tendencia a justificar sus acciones como respuestas a la provocación.

También para Collell y Escude (2004) hay dos tipos, 1) de predominio dominante, utiliza agresividad proactiva (como herramienta para conseguir su objetivo), considera que sus hechos tienen justificación en tanto la víctima se merece lo que le pasa, con necesidad de poder, siente placer en el dominio y tiene alta actitud hacia la violencia (Berkowitz, 1996; Olweus, 1994), sus acciones son premeditadas y sus víctimas son seleccionadas dependiendo la condición mental que justifiquen esta acción, son manipuladores y podrían presentar habilidades sociales ante los adultos (Salmivalli, Karhunen y Kirsti, 1996) pero con sus pares son impopulares y rechazados (Malik y Furman 1993, citado en Aviles, 2005) con problemas de adaptabilidad y no son cooperativos, (Bierman, Smoot y Aumiller 1993, citados en Granda, 2001); 2) dominante ansioso, utiliza la agresividad reactiva al explotar ante situaciones de estrés, tensión o conflicto (Díaz, 2003; Crick y Dodge 1994, citados en Collell y Escude, 2004) con un sesgo atribucional que lo lleva a interpretar como hostiles diferentes situaciones. Podrían ser populares por la acción de la cultura violenta que lo privilegia (Aviles, 2009; Cerezo, 1998).

Además existen agresores secuaces que son seguidores de líderes agresores (Aviles, 2009) y re- forzadores de los actos de su líder y se protegen con los beneficios de la relación grupal. También están el intimidador según el género, por ejemplo los hombres se caracterizan por patrones de agresividad física y directa con golpes, patadas o uso de intimidación psicológica en apodos, insultos, amenazas y actitudes negativistas y desafiantes, a diferencia de las mujeres que tienen tendencia hacia la intimidación psicológica con preferencia verbal e indirecta como la exclusión, hablar mal de otra persona, inventar o decir mentiras, etc., (Piñuel y Oñate, 2007; Cerezo, 1998; Olweus, 1998; Ortega y Monks, 2005).

Además se ha asociado al agresor con déficit cognitivos en atención, concentración, funciones ejecutivas, solución de problemas y razonamiento abstracto (Aviles, 2009) en donde el $15 \%$ de los agresores presentan cuadros similares al TDAH (Jiménez, 2005; Infante et al., 2003), con mayor frecuencia a repetir materias y grados escolares, el $60 \%$ tiene actitud negativa hacia el colegio, la gran mayoría se escapan del aula y algunos son sorprendidos consumiendo alcohol o drogas en espacio escolar (Cerezo, 2001; Llorente, 2005), tienen déficit en habilidades sociales como empatía, solidaridad y cooperación, y no aprovechan los beneficios de la socialización escolar (Infante y colaboradores, 2003).

Sus déficit en habilidades sociales se integran con el consumo temprano de alcohol, drogas, iniciación sexual y conducta delincuencial (Torres, 2005; Garnefski y Diekstra, 1997), aspectos que se referencia en casi el $40 \%$ de los estudiantes (Ruchkin, Koposov, Eisemann y Hägglöf 2001, citados en Muñoz, Carreras y Braza, 2004) y que según Moreno (2011):

Son estudiantes boicoteadores del trabajo del profesor (...), violan las normas establecidas en el aula (tiran cosas, desordenan la clase, falta de orden en la entrada y salida, generan ruidos), alteran el desarrollo de las tareas (se niegan a participar en las actividades, comentarios vejatorios ante la tarea, hacen otras actividades, no traen el material requerido), se oponen a la autoridad (interrumpen cuando habla el profesor, no obedecen las órdenes, 
amenazan al profesor), agreden a compañeros (se ríen de ellos, agreden físicamente, insultan al compañero en clase), impulsivos, hiperactivos, problemas de atención, hostiles, déficit en el control de la ira y agresividad (p. 84).

Comportamientos también referenciados en Erazo (2013) (Torrego y Moreno 1999, citados en Muñoz, 2004) y que según Moreno (2006), deben definirse como trastornos de la conducta antisocial y clasificarse en 6 grupos dentro del aula, a) disrupción en las aulas, b) problemas de atención y disciplina (conflictos entre profesorado y alumnado), c) maltrato entre compañeros (intimidación), d) vandalismo y daños materiales, e) violencia física (agresiones, extorsiones) y f) acoso sexual (García 2001, citado en Muñoz 2004; Moreno, 2011).

La prevalencia es 3 a 1 a favor de los niños (Cerezo, 1998), en España el 8.6 \% es agresor, de los cuales el $79.3 \%$ son niños y un $57.4 \%$ ha trabajo en complicidad para agredir a otro (Serrano e Iborra, 2005). En Colombia, Paredes (2008) describe que en Cali, el $43.6 \%$ admiten haber agredido y un 10.37 \% lo hace diariamente, en Bogotá, Zubiría, Peralta y Castilla (2009) nombran que 1 de 10 estudiantes es agresor.

La víctima es el estudiante que recibe el impacto del agresor, permitiendo los comportamientos maltratantes en contra de su voluntad y encajando en el comportamiento del agresor dominante (Olweus 1993, citado por Costell y Escode, 2004). Aviles (2009) ha identificado dos tipos de víctima, 1) víctima pasiva o receptora, es indefensa y podría ser rechazada por sus compañeros, siendo abandonada ante una contienda con el agresor, no tiene amigos y es excluido por el grupo de su clase, tiene baja autoestima, ansiedad, preocupación constante y representación de debilidad; 2 ) es la víctima reactiva, que se diferencia por su actitud de defensa ante su agresor, en un intento desesperado por cambiar la balanza y en que el objetivo no es alcanzado, siendo humillado y golpeado con mayor intensidad por parte de su rival.

En España un 50 \% de las víctimas son pasivas, pero un $36.2 \%$ insultan al agresor, el $19.8 \%$ intenta pegarle y desafortunadamente un $19.8 \%$ le hace lo mismo a otro compañero más débil, (Serrano e Iborra, 2005) siendo su rol cambiante en ocasiones víctima y en otra agresor, (Aviles, 2005), similar condición reporta Piñuel y Oñate (2007), en que del $38 \%$ de las víctimas, un $18,6 \%$ no responde, pero un $19,7 \%$ realiza hostigamientos contra otros, y un $11 \%$ se convertirá en acosador con cambio de rol según la condición.

La víctima es escogida por el agresor de forma premeditada en la que se preferencian estudiantes inseguros, poco agresivos, físicamente débiles, temerosos y con rasgos físicos dominantes como obesidad, gafas o cicatrices, pueden ser escogidos por pertenecer a una minoría étnica como indígena, afro $u$ homosexual, o lo que un agresor considere como minoría, ejemplo, en un grupo que predominen mujeres un hombre es minoría o falta de recursos económicos, además juega en la valoración la posibilidad que la víctima pueda ser respaldada.

El impacto siempre es negativo y se debe valorar no solo de forma física, sino psicológica y afectiva, siendo común los cuadros de ansiedad, estrés postrauma y pensamientos obsesivos con contenidos que indican que algo malo puede pasar. Por lo general la víctima se calla, se aleja y se autoexcluye del grupo y no denuncia el hecho, teniendo que sufrir en soledad, de ahí que un $18.1 \%$ no se lo comenta a nadie, un $5.2 \%$ considera que no le interesa a nadie, tienen miedo un $3.4 \%$, y cree que es peor informar un 1.7 \% (Defensor del Pueblo, 2007).

Presentan cuadros afectivos de ansiedad, pesadillas, cambios de sueño, trastornos de alimentación, depresión y tendencia suicida, somatización, desmotivación escolar, bajo rendimiento académico, pierden sus pertenencias continuamente o están deterioradas o rotas, presentan rasguños, golpes o hematomas, con baja integración, no tienen amigos y son rechazados, no se puede olvidar que el inicio de la investigación en intimidación se reporta por el suicidio de tres estudiantes que fueron acosadas en instituciones educativas de Noruega (Olweus citado en Mertz, 2006) o por las condiciones alarmantes en trastornos mentales como los descritos (Barone 1997, citado por 
Green, 2007) en la narración de dos adolescentes en Littleton, Colorado que asesinaron a 13 personas y terminaron en suicidio como forma de venganza por el acoso continuo, o en el 2005 en Lago Rojo al norte de Minnesota, un estudiante de 16 años asesino a un guardia, a un maestro y a cinco estudiantes en una historia en la que se involucraba la intimidación. Se cree que el $89.3 \%$ de las víctimas en Estados Unidos presentan desequilibrios emocionales, en España la situación es similar y se reporta un $58 \%$ de víctimas con trastorno de estrés postrauma e ideación suicida (Araceli, Iñaki y Zabala 2005, citado en Muñoz, 2008).

Costell y Escode (2004) describen que la presión continua confunde a la víctima al autoconsiderarse culpable y causante de la intimidación, y se justifica con pensamientos que nombran su condición física o la no aceptación de reglas que se supone debe saber (no pasar por un pasillo, pedir explicación en clase, ser inteligente, etc.). En ocasiones la víctima al ser consciente de su comportamiento no adaptable a las condiciones del agresor, termina convirtiéndose en un seguidor de otro agresor, un $17.2 \%$ de los agresores fueron en el pasado agredidos frecuentemente y es frecuente que las versiones de la familia y el docente sean contradictorias con la realidad, ya que estos los perciben como inteligentes y amigables.

La prevalencia en Estados Unidos es del $17 \%$, de los cuales el $45 \%$ son niños y el $55 \%$ niñas (Green, 2007). En España es del 25 \% (Defensor del Pueblo, 2007), Piñuel y Oñate (2007) en Madrid reportan un $24 \%$, y Ortega y Monks (2005) describen que en zonas rurales es del $16,1 \%$, y un $39 \%$ nombra sufrir esta situación durante meses, en preescolar es del 14,1 \%. En Latinoamérica, Gálvez-Sobral (2011) indica que en Guatemala es del $21 \%$. En Colombia, Zubiría et al., (2009) concluyen que dos estudiantes por salón son agredidos frecuentemente, implicando para Bogotá, al menos 90.000 estudiantes, en Cali, Paredes (2008) describe que es del $51.4 \%$ y Granda (2001) considera que un $45 \%$ de las víctimas es acosado por más de un agresor.

En el escenario de la intimidación está el observador, quien es el testigo de estos hechos grotescos, es pasivo y no interviene, ni denuncia estas acciones (Aviles, 2009). Se justifica en la creencia egocéntrica de pensar que no es un asunto de él, desensibilizándose ante el dolor y siendo tolerante a la crueldad o porque comparte ideas de racismo, xenófobas o religiosas. Existe un observador que considera injusta la intimidación pero no interviene por miedo a ser intimidado, o no reconoce un positivo protocolo de denuncia (Aviles, 2009). En España un 45 \% de observadores intervienen en la agresión pero un $19.3 \%$ no lo hace, y un $84 \%$ ha observado intimidación psicológica, un $77 \%$ maltrato físico, un $17.2 \%$ actos vandálicos y un $1,3 \%$ abuso sexual, (Serrano e Iborra, 2005), en Bogotá (Colombia) 3 de 10 estudiantes es observador y para un 34 \% es común (Zubiría et al., 2009).

\section{Tipos de intimidación escolar}

La intimidación se clasifica de forma directa o indirecta. La directa refiere a los actos que se pueden observar con una interacción abierta entre el agresor y la víctima, y la indirecta refiere al proceso oculto y solapado sin interacción lineal, en donde el agresor se oculta o intimida a través de sus secuaces (Aviles, 2009; Olweus, 1998), las dos permiten la realización de ocho formas de intimidación entre las que están:

1. Intimidación física, refiere a la acción directa en que la víctima es agredida por contacto físico con golpes, puñetazos, etc., según Green (2007) un $10 \%$ de los estudiantes en Estados Unidos ha terminado en un hospital por lesiones. Se incluyen las acciones de tipo antisocial como robar, encerrar o retener a las víctimas en el baño o agredirlas por medio de armas, por ejemplo en Málaga (España) a un $4.8 \%$ de los estudiantes les ha pasado esta situación (Infante, 2003), el Defensor del Pueblo (2007), describe que a 16 de 100 le esconden las cosas, a un 7 $\%$ los roban y a un $4 \%$ se las rompen, y Serrano e Iborra (2005) nombran que un $6 \%$ ha vivido experiencias de vandalismo, un $1 \%$ ha sido extorsionado económicamente, y Gálvez-Sobral en Guatemala (2011) describe que 5 de 100 son víctimas físicas, y 8 de 100 son agredidos por pandillas. En Chile, Mertz (2006), describe que 1 de 10 es agredido y un $8 \%$ ha sido robado en la escuela, en Colombia, Paredes (2008) describe 
que en Cali un $1.5 \%$ de estudiantes han sido amenazados con armas rusticas como tijeras, y en Bogotá, Zubiría, describe que es más común la agresividad física en instituciones educativas de tipo oficial que privado.

2. Intimidación psicológica o verbal, se caracteriza por el uso del lenguaje como una forma de dominar, afectando la personalidad y la condición afectiva de la víctima (Gálvez-Sobral, 2011). (Evans 1999, citado por Gálvez-Sobral, 2011), explica que es la más frecuente y que se puede dar en al menos 15 formas entre las que están, contener, contradecir, despreciar, ataques disfrazados de chiste, bloquear y desviar, acusar y culpar, juzgar y criticar, trivializar, destruir, amenazar, insultar, negar y manifestar ira abusiva. En España con un 26,7 \% es el apodo el más común y es mayor el fenómeno entre mujeres que en hombres (Defensor del Pueblo; 2007). En Argentina, se denuncian hechos como el molestar al compañero en un $30 \%$, bromear $28 \%$, insultar $23 \%$ y burlarse $13 \%$ (Pautasso, 2006), en Chile es del 48 \% (Mertz, 2006) y en Colombia es del $30 \%$ en instituciones privadas y $40 \%$ en públicas (Zubiría et al., 2009).

3. La amenaza, tiene un alto impacto en la víctima, ocasionando angustia y estrés continuo debido a la espera que sufre el estudiante para cumplirse la amenaza, (Aviles, 2004). Según el Defensor del Pueblo (2007) un $6.4 \%$ de los agresores utiliza este método y un $0.7 \%$ de las víctimas describen haber sido amenazados con armas para inculcarles miedo o para obligarlos a hacer cosas en contra de su voluntad. En Guatemala un $2.5 \%$ es amenazado y es más frecuente en niños (Gálvez-Sobral, 2011).

4. La manipulación tiene el objetivo de distorsionar la imagen social de la víctima buscando el rechazo y la exclusión del grupo escolar, esta manipulación lleva a otros a sumarse al grupo de acosadores de una forma involuntaria creando un error de atribución de la víctima. Algunos intimidadores buscan que su víctima llore para ser mostrados como débiles y estigmatizarlas (Voors 2005, citado por Gálvez-Sobral, 2011).

5. La coacción pretende que la víctima realice acciones en contra de su voluntad ejerciendo dominio y sometimiento, este incluye la realización de hechos humillantes como quitarle la ropa, permitir abuso sexual, entre otras.

6. Exclusión social, refiere a la acción de separar a la víctima del grupo escolar, para ello se ignora, excluye y menosprecia a la víctima, haciendo que se sienta rechazada y no encaje entre las pautas del grupo. El agresor manipula a otros para realizar el bloqueo social haciendo prohibiciones como no poder jugar en grupo o hacer que nadie hable con la víctima, quebrando su red de apoyo. En España, se da en un 10 \% (Granda, 2001). En Guatemala, 7 de 100 son excluidos de acciones lúdicas, grupales y académicas (Gálvez-Sobral, 2011), en Bogotá (Colombia) (Cepeda et al., 2008), en instituciones oficiales de Ciudad Bolívar, describe que es del $54 \%$.

7. Exclusión por minoría, es una forma de intimidar que se justifica por pertenecer a una minoría de diferentes tipos, puede ser étnica, racial, económica, etc.

8. Ciberbullying, forma de intimidar a través de la internet o redes sociales, para ello se inventa o difama la figura de la víctima con el fin que sea humillada por otros (Aviles, 2009), en España, es del $7 \%$.

9. Acoso sexual, es una forma de agredir a través del uso del manoseo, propuestas indecentes, violación o manipulación de las víctimas a través de fotografías y videos sexuales que son grabados sin el consentimiento de la víctima, pero se amenaza con ser expuestos. Según Gálvez-Sobral (2011), en Guatemala un 1 \% ha sido agredido sexualmente, y son comunes las denuncias de víctimas que han sido violentadas en la internet por la exposición de videos o fotografías ilegal.

Estas consideraciones afectan el desarrollo social de los estudiantes y también de los profesores y la comunidad académica, creando ambientes de tensión y estrés, (Abromovay, 2005; Estévez, Musitu y Herrero, 2005) y notándose en el bajo rendimiento académico, problemas de aprendizaje, depresión y tendencia suicida y falta de motivación escolar. 


\section{Metodología-instrumentos}

Se realiza una investigación de tipo cuantitativa con diseño descriptivo en una muestra no probabilística de 1.300 estudiantes, 752 (57.85\%) chicos y $548(42.15 \%)$ chicas en edades de 9 a 11 años (13.38\%), 12 a 14 (73.61\%) y 15 a17 (13\%), de los grados 6,7 y 8 de 5 instituciones oficiales (Comercial del Norte, Ulloa, Metropolitano, El Liceo y Carlos M. Simmons), 513 padres y 81 docentes del municipio de Popayán, Colombia. El análisis se realizó con SPSS (versión libre) y frecuencias relativas.
La variable de intimidación y tipología, se midió con la lista de chequeo de Arora (1989), denominada "mi vida en la escuela" y validada por Aviles en el 2002, como complemento a su cuestionario de intimidación y maltrato entre iguales.

Para la variable agresores y actitudes se utilizó el cuestionario de actitudes hacia la violencia en centros educativos (CAHV-25) de Ruiz, Llor, Puebla y Llor (2009) de la Universidad de Murcia, validado en lengua española. Y las variables percepción de profesores y padres se utiliza el preconcimei de Aviles (2002, citado en Aviles y Monjas, 2005).

\section{Resultados}

Tabla 1.

Intimidación física - tipos - edad.

\begin{tabular}{|c|c|c|c|c|c|c|c|c|c|}
\hline \multirow{2}{*}{$\begin{array}{l}\text { Hombres: } 752 \text { (57.85 \%) - } \\
\text { Mujeres; } 548 \text { (42.15\%). N: } 1300=100 \%\end{array}$} & \multicolumn{3}{|c|}{ a veces (\%) } & \multicolumn{3}{|c|}{ más de una vez } & \multicolumn{3}{|c|}{ bastante (\%) } \\
\hline & $M$ & $\mathrm{~F}$ & $=$ & $\mathrm{H}$ & $M$ & $=$ & $\mathrm{H}$ & $M$ & $=$ \\
\hline Intentaron pegarme & 15 & 7 & 22 & 5 & 4 & 9 & 5 & 2 & 7 \\
\hline Intentó darme patadas & 17 & 5 & 22 & 4 & 1 & 5 & 3 & 0 & 3 \\
\hline Me ha quitado alguna cosa & 19 & 10 & 29 & 6 & 4 & 10 & 4 & 1 & 5 \\
\hline $\begin{array}{l}\text { Edad: } 9 \text { a 11: }(174=100 \%)-12 \text { a } 14: \\
(957=100 \%)-15 \text { a } 17(169=100 \%) .\end{array}$ & \multicolumn{3}{|c|}{ a veces (\%) } & \multicolumn{3}{|c|}{ más de una vez } & \multicolumn{3}{|c|}{ bastante (\%) } \\
\hline$N=1300$. & $9-11$ & $12-14$ & $15-17$ & $9-11$ & $12-14$ & $15-17$ & $9-11$ & $12-14$ & $15-17$ \\
\hline Intentaron pegarme & 21.8 & 22.8 & 21.3 & 5.1 & 6.9 & 5.3 & 6 & 6.3 & 7.2 \\
\hline Intentó darme patadas & 20.1 & 21.1 & 20.7 & 3.4 & 5.4 & 4.1 & 6 & 4.5 & 4.3 \\
\hline Me ha quitado alguna cosa & 21.2 & 28.9 & 31.3 & 8.6 & 9.8 & 10.6 & 5.8 & 6.8 & 5.3 \\
\hline
\end{tabular}

Fuente. Erazo (2013, p. 46).

Describe que al $38 \%$ de la muestra le han intentado pegar siendo bastante para el $7 \%$, para los chicos es del $5 \%$ y las niñas del $2 \%$, además al $30 \%$ intentan darle patadas y al $44 \%$ le han quitado algo. Esto sucede entre los 9 a 17 años, su frecuencia puede ser a veces en el $20 \%$ a $30 \%$, y bastante al $4.3 \%$ a $7.2 \%$ de intentar golpear, patear o quitar algo.

Se describe que les dicen apodos al $69.6 \%$, para los 9-11 años es del 55.6\%, de los 12-14 años es del $72.9 \%$, y entre los 15 a 17 años es del $69.7 \%$, le han gritado al $45.2 \%$, amenazan con darles una paliza al $26 \%$ y que los acusarán de algo al $25.3 \%$, coaccionan al $23 \%$, dicen mentiras del estudiante al $53.3 \%$, de los $9-11$ años es del $45.8 \%$, de los 12 14 del $57.4 \%$ y de los $15-17$ años es del $63.3 \%$, el $32.6 \%$ siente que lo tratan de forma desagradable por como es, y al $24.1 \%$ son desagradables por el color de la piel, entre los 9-11 años es del $16.7 \%$, de los 12-14 años es del $16.2 \%$ y entre los 15-17 años es del $13.5 \%$. 
Tabla 2.

Intimidación psicológica - tipos - edad.

\begin{tabular}{|c|c|c|c|c|c|c|c|c|c|}
\hline \multirow{2}{*}{ 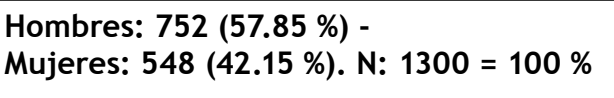 } & \multicolumn{3}{|c|}{ a veces $(\%)$} & \multicolumn{3}{|c|}{ más de una vez } & \multicolumn{3}{|c|}{ bastante ( \%) } \\
\hline & $\mathrm{H}$ & $M$ & $=$ & $\mathrm{H}$ & $M$ & $=$ & $\mathrm{H}$ & $M$ & $=$ \\
\hline Me ha dicho apodos, (sobrenombres) & 29 & 19 & 48 & 7 & 3 & 10 & 9 & 2.6 & 11.6 \\
\hline Me gritó & 20 & 13 & 33 & 3.8 & 2.6 & 6.4 & 4 & 1.8 & 5.8 \\
\hline \multicolumn{10}{|c|}{ Amenaza - Coacción } \\
\hline Me dijeron que me darían una paliza & 13 & 5 & 18 & 3.6 & 0.8 & 4.4 & 3 & 0.6 & 3.6 \\
\hline Me dijeron que me acusarían & 11 & 7 & 18 & 2 & 1 & 3 & 3 & 1.3 & 4.3 \\
\hline Me hizo hacer algo que no quería hacer & 13.6 & 4 & 17.6 & 2 & 0.6 & 2.6 & 2 & 0.8 & 2.8 \\
\hline \multicolumn{10}{|c|}{ Manipulación - Exclusión social } \\
\hline Dijeron una mentira acerca de mí & 20 & 18 & 38 & 3.1 & 5 & 8.1 & 3 & 4.2 & 7.2 \\
\hline Fue desagradable porque yo soy diferente & 11 & 9 & 20 & 2.8 & 2.8 & 5.6 & 3.8 & 3.2 & 7 \\
\hline Ha sido grosero acerca del color de mi piel & 9 & 6.8 & 15.8 & 3 & 2 & 5 & 2 & 1.3 & 3.3 \\
\hline \multirow{2}{*}{$\begin{array}{l}\text { Edad: } 9 \text { a } 11:(174=100 \%)-12 \text { a } 14: \\
(957=100 \%)-15 \text { a } 17(169=100 \%) \\
N=1300\end{array}$} & \multicolumn{3}{|c|}{ a veces (\%) } & \multicolumn{3}{|c|}{ más de una vez } & \multicolumn{3}{|c|}{ bastante ( \%) } \\
\hline & $9-11$ & $12-14$ & $15-17$ & $9-11$ & $12-14$ & $15-17$ & $9-11$ & $12-14$ & $15-17$ \\
\hline Me ha dicho apodos & 34.4 & 49.9 & 50.3 & 9.7 & 10.6 & 8.2 & 11.5 & 12.4 & 11.2 \\
\hline Dijeron mentiras de mí & 29.8 & 36.8 & 42 & 9.7 & 12.12 & 13 & 6.3 & 8.5 & 8.3 \\
\hline Desagradable, soy diferente & 19.5 & 18.6 & 21.8 & 1.7 & 5 & 3.5 & 5.3 & 6.8 & 9.4 \\
\hline Grosero acerca del color de piel & 9.2 & 9.5 & 11.8 & 1.7 & 2.1 & 0 & 5.8 & 4.6 & 1.7 \\
\hline
\end{tabular}

Fuente. Erazo (2013, p. 46).

Tabla 3.

Intencionalidad de la intimidación - personalidad.

\begin{tabular}{|c|c|c|c|c|c|c|c|c|c|}
\hline \multirow{2}{*}{$\begin{array}{l}\text { Edad: } 9 \text { a } 11:(174=100 \%)-12 \text { a } 14: \\
(957=100 \%)-15 \text { a } 17(169=100 \%) \\
N=1300\end{array}$} & \multicolumn{3}{|c|}{$\begin{array}{l}\text { muy }(. . .) \text { y en } \\
\text { desacuerdo }\end{array}$} & \multicolumn{3}{|c|}{ de acuerdo (\%) } & \multicolumn{3}{|c|}{ muy de acuerdo (\%) } \\
\hline & $9-11$ & $12-14$ & $15-17$ & $9-11$ & $12-14$ & $15-17$ & $9-11$ & $12-14$ & $15-17$ \\
\hline $\begin{array}{l}\text { Me siento fuerte después de insultar a un } \\
\text { compañero }\end{array}$ & 77.2 & 80.2 & 78.8 & 4 & 4.2 & 10.6 & 6.5 & 5.2 & 5.6 \\
\hline $\begin{array}{l}\text { Me siento importante cuando demuestro } \\
\text { fuerza }\end{array}$ & 76.4 & 67.6 & 57.6 & 4 & 9.7 & 11.1 & 7.6 & 8.2 & 9 \\
\hline Me siento bien agrediendo a compañeros & 90.5 & 75.6 & 69.9 & 2.3 & 5.4 & 8.8 & 3.2 & 6.6 & 5.2 \\
\hline
\end{tabular}

Fuente. Erazo (2013, p. 48).

El intimidador se siente fuerte al insultar a un compañero de los 9 a 11 años en $10.5 \%$, de los 12 a 14 el $9.4 \%$, y 15 a 17 el $16.2 \%$, es importante al demostrar la fuerza de los 9 a 11 años el 11.6 $\%$, de 12 a 14 años el $17.9 \%$, y 15 a 17 años el 20.1 $\%$, y se sienten bien agrediendo de los 9 a 11 años el $5.5 \%$, de los $12-14$ el $12 \%$, y a los $15-17$ años el $14 \%$.
La tabla describe cómo al 20 \% le gusta poner apodos, de los 9 a 11 años lo hace el $11 \%$, de 12 a 14 años el $16.1 \%$, y de 15 a 17 años el $22.4 \%$, le es divertido meterse con profesores al $11.4 \%$, para los 9 a 11 años el $8 \%$, de 12 a 14 años el $22.4 \%$ y de 15 a 17 años el $14.7 \%$, y es divertido meterse con compañeros al $12.6 \%$, para los 9 a 11 años es del $5.8 \%, 12$ a 14 es el $11.2 \%$ y 15 a 17 años es del $14 \%$. 
Tabla 4.

Intimidación y diversión.

\begin{tabular}{|c|c|c|c|c|c|c|c|c|c|}
\hline \multirow[t]{2}{*}{$N=1300-100 \%$} & & \multicolumn{2}{|c|}{$\begin{array}{l}\text { muy }(. . .) \text { y en } \\
\text { desacuerdo } \\
(\%)\end{array}$} & \multicolumn{2}{|c|}{ indeciso (\%) } & \multicolumn{2}{|c|}{ de acuerdo } & \multicolumn{2}{|c|}{$\begin{array}{l}\text { muy de } \\
\text { acuerdo }\end{array}$} \\
\hline & & $\mathrm{H}$ & M & M & $\mathrm{H}$ & M & $\mathrm{H}$ & $\mathrm{H}$ & M \\
\hline Me gusta poner apodos & & 37.8 & 34.2 & 34.2 & 5.2 & 3.2 & 9 & 6.8 & 2.2 \\
\hline Meterse con los profesores es divertido & & 39.4 & 36 & 36 & 5.8 & 2 & 2.8 & 4.4 & 2.2 \\
\hline Resulta divertido meterme con compañeros & & 43.8 & 36 & 36 & 4.6 & 3.2 & 4.2 & 4.2 & 1.4 \\
\hline \multirow{2}{*}{$\begin{array}{l}\text { Edad: } 9 \text { a } 11(174: 100 \%)-12 \text { a } 14 \\
(957=100 \%), 15 \text { a } 17(169=100 \%) \\
N=1300\end{array}$} & \multicolumn{3}{|c|}{$\begin{array}{c}\text { muy (...) y en } \\
\text { desacuerdo }\end{array}$} & \multicolumn{3}{|c|}{ de acuerdo (\%) } & \multicolumn{3}{|c|}{ muy de acuerdo (\%) } \\
\hline & $9-11$ & $12-14$ & $15-17$ & $9-11$ & $12-14$ & $15-17$ & $9-11$ & $12-14$ & $15-17$ \\
\hline Me gusta poner apodos & 82 & 71.2 & 65.2 & 6.4 & 9.6 & 9.2 & 4.6 & 6.5 & 13.2 \\
\hline Meterse con profesores es divertido. & 88.6 & 65.2 & 74.4 & 1.7 & 9.2 & 7.1 & 6.3 & 13.2 & 7.6 \\
\hline Resulta divertido meterme con compañeros & 89.6 & 79.3 & 73.9 & 2.8 & 6.4 & 9.4 & 3 & 4.8 & 4.6 \\
\hline
\end{tabular}

Fuente. Erazo (2013, p. 49).

Tabla 5.

Intimidación para resolver problemas y manejar relaciones.

\begin{tabular}{|c|c|c|c|c|c|c|c|c|c|}
\hline \multirow{2}{*}{\multicolumn{2}{|c|}{$N=1300-100 \%$}} & \multicolumn{2}{|c|}{$\begin{array}{c}\text { muy }(. . .) \text { y en } \\
\text { desacuerdo } \\
(\%)\end{array}$} & \multicolumn{2}{|c|}{ indeciso (\%) } & \multicolumn{2}{|c|}{ de acuerdo } & \multicolumn{2}{|c|}{$\begin{array}{l}\text { muy de } \\
\text { acuerdo }\end{array}$} \\
\hline & & $\mathrm{H}$ & M & M & $\mathrm{H}$ & M & $\mathrm{H}$ & $\mathrm{H}$ & M \\
\hline $\begin{array}{l}\text { En la escuela suelo resolver mis problemas us } \\
\text { la fuerza }\end{array}$ & ndo & 41.8 & 37.8 & 7 & 3.2 & 5.4 & 2.8 & 3 & 2 \\
\hline Pegando los demás te respetan & & 32.6 & 35.4 & 9.4 & 3.8 & 5.2 & 2.2 & 5.8 & 2.2 \\
\hline Controlo a mis amigos por la amenaza & & 48.2 & 36.2 & 4.2 & 3.8 & 3 & 1.4 & 2.1 & 1.4 \\
\hline \multirow{2}{*}{$\begin{array}{l}\text { Edad: } 9 \text { a } 11:(174=100 \%)-12 \text { a } 14: \\
(957=100 \%)-15 \text { a } 17(169=100 \%) \\
N=1300\end{array}$} & \multicolumn{3}{|c|}{$\begin{array}{c}\text { muy }(\ldots) \text { y en } \\
\text { desacuerdo }\end{array}$} & \multicolumn{3}{|c|}{ de acuerdo (\%) } & \multicolumn{3}{|c|}{ muy de acuerdo (\%) } \\
\hline & $9-11$ & $12-14$ & $15-17$ & $9-11$ & $12-14$ & $15-17$ & $9-11$ & $12-14$ & $15-17$ \\
\hline Suelo resolver problemas a la fuerza & 73.3 & 75.2 & 76.2 & 5.7 & 8.6 & 10 & 3.3 & 5.2 & 5.2 \\
\hline Pegando te respetan & 84.4 & 71.5 & 70 & 4.6 & 7.1 & 8.8 & 4.5 & 9 & 8.2 \\
\hline Controlo a amigos por amenaza & 89 & 83 & 86.3 & 1.7 & 4.8 & 4.1 & 3.4 & 4 & 2.9 \\
\hline
\end{tabular}

Fuente. Erazo (2013, p. 52).

La tabla describe que se utiliza la fuerza para resolver problemas en el 19. $2 \%$ de los 9 a 11 años está de acuerdo, el $9 \%$ de los 12 a 14 años, el 13.8 $\%$ y los 15 a 17 años es el $15.2 \%$, y utiliza golpes para ser respetado el $15.4 \%$ en donde están de acuerdo y muy de acuerdo entre los 9 a 11 años el $9.1 \%$, de los 12 a 14 años el $16.1 \%$, y entre los 15 a 17 años el $17 \%$, y utilizan la amenaza para controlar a otro el $8.9 \%$, de los 9 a 11 años el 5.1 $\%$, de los 12 a 14 años el $8.8 \%$ y de los 15 a 17 años el $7 \%$. 
Tabla 6.

Intimidación como defensa.

\begin{tabular}{|c|c|c|c|c|c|c|c|c|}
\hline \multirow[t]{2}{*}{$N=1300-100 \%$} & \multicolumn{2}{|c|}{$\begin{array}{c}\text { muy }(. . .) \text { y en } \\
\text { desacuerdo } \\
(\%)\end{array}$} & \multicolumn{2}{|c|}{ indeciso (\%) } & \multicolumn{2}{|c|}{ de acuerdo } & \multicolumn{2}{|c|}{$\begin{array}{l}\text { muy de } \\
\text { acuerdo }\end{array}$} \\
\hline & $\mathrm{H}$ & M & M & $\mathrm{H}$ & M & $\mathrm{H}$ & $\mathrm{H}$ & M \\
\hline $\begin{array}{l}\text { Me parece bien meterme con un compañero cuando } \\
\text { se lo ha ganado }\end{array}$ & 36 & 31.5 & 7.4 & 4.6 & 8.2 & 3.4 & 0.9 & 3.6 \\
\hline Me gustaría pegar a los que me insultan & 27.6 & 28.8 & 9.8 & 5.4 & 9.2 & 3.2 & 9.2 & 4.8 \\
\hline La violencia es adecuada para defenderse & 37 & 36 & 8.2 & 2.8 & 7.2 & 2 & 7 & 2.6 \\
\hline Si me insultara, me defendería atacándole & 38.8 & 37 & 9.8 & 3.8 & 5.4 & 2.8 & 3.8 & 2.6 \\
\hline \multirow[t]{2}{*}{ Edad } & \multicolumn{2}{|c|}{$\begin{array}{c}\text { muy (...) y en } \\
\text { desacuerdo }\end{array}$} & \multicolumn{3}{|c|}{ de acuerdo (\%) } & \multicolumn{3}{|c|}{ muy de acuerdo (\%) } \\
\hline & $12-14$ & $15-17$ & $9-11$ & $12-14$ & $15-17$ & $9-11$ & $12-14$ & $15-17$ \\
\hline Me parece bien meterme (...) & 58.9 & 62.6 & 5.9 & 12.1 & 14.2 & 11.2 & 9.1 & 13.6 \\
\hline Pegar a los que me insultan & 60.4 & 50.6 & 10.9 & 12.9 & 14.7 & 9.8 & 13.6 & 15.4 \\
\hline La violencia para defenderse & 68.9 & 66 & 6.8 & 9 & 8.9 & 2.8 & 10 & 10.4 \\
\hline Me defendería atacándole & 72.8 & 63.8 & 7.4 & 7.7 & 11.2 & 4 & 5.2 & 11.8 \\
\hline
\end{tabular}

Fuente. Erazo (2013, p. 57).

Los estudiantes consideran que está bien meterse o agredir a alguien si se lo ha ganado en un 16.1 $\%$, de los 9 a 11 años el $17.1 \%$, de los 12 a 14 años el $21.2 \%$, y de los 15 a 17 años el $27.9 \%$, y golpearía a los que lo han insultado el $27.4 \%$, en donde para los 9 a 11 años el $20.7 \%$, de los 12 a 14 años el $26.5 \%$, y entre los 15 a los 17 años el $30.1 \%$, y piensa usar la violencia para defenderse el $18.8 \%$ de 9 a 11 años el $9.6 \%$, de los 12 a 14 años el 19 $\%$, y de los 15 a 17 años el $19.3 \%$, y se defendería atacando el $14.6 \%$, de 9 a 11 el $11.4 \%$, de 12 a 14 años el $12.9 \%$, y de 15 a 17 años el $23 \%$.

Tabla 7.

Intimidación y percepción de los profesores y padres.

\begin{tabular}{|c|c|c|c|c|}
\hline $\begin{array}{l}\text { Tabla de profesores } \\
N=81-100 \%\end{array}$ & $\begin{array}{c}\text { muy }(\ldots) \\
\text { y en } \\
\text { desacuerdo }\end{array}$ & $\begin{array}{l}\text { indeciso } \\
\text { (\%) }\end{array}$ & $\begin{array}{l}\text { de } \\
\text { acuerdo } \\
(\%)\end{array}$ & $\begin{array}{l}\text { muy de } \\
\text { acuerdo }\end{array}$ \\
\hline $\begin{array}{l}\text { Las agresiones y situaciones violentas son un grave problema en mi } \\
\text { centro }\end{array}$ & 42.1 & 22.2 & 27.1 & 8 \\
\hline $\begin{array}{l}\text { El propio profesorado es en ocasiones el objeto de ataque del } \\
\text { alumnado }\end{array}$ & 74 & 7.4 & 16 & 2.4 \\
\hline $\begin{array}{l}\text { Para eliminar los problemas de violencia es necesario que el equipo } \\
\text { completo de profesorado tome consciencia y se decida a actuar }\end{array}$ & 17.2 & 11.1 & 35.8 & 35.8 \\
\hline $\begin{array}{l}\text { El profesorado, sin ayuda de otros profesionales, no está preparado } \\
\text { para resolver los problemas de malas relaciones }\end{array}$ & 33.2 & 19.7 & 33.3 & 13.5 \\
\hline $\begin{array}{l}\text { Como profesor, considero tan importantes los problemas de } \\
\text { violencia e intimidación como los que tiene que ver con el } \\
\text { rendimiento académico }\end{array}$ & 11 & 2.4 & 38.2 & 48.1 \\
\hline $\begin{array}{l}\text { La carga lectiva e institucional actúa como una exigencia que impide } \\
\text { dedicarse a asuntos como los problemas de relaciones interpersonales }\end{array}$ & 11 & 2.4 & 38.2 & 48.1 \\
\hline
\end{tabular}




\begin{tabular}{lcccc}
\hline \multicolumn{1}{c}{ Percepción padres - N= 513 - 100 \% } & & \\
\hline En el instituto en que cursa estudios mi hijo existe intimidación & 47.9 & 20.6 & 14.4 & 17 \\
\hline Creo que mi hijo no podrá participar nunca en actos de intimidación & 30.3 & 17.3 & 16.6 & 35 \\
\hline Si mi hijo tuviera algún problema de intimidación me lo contaría & 7.5 & 11.8 & 16.5 & 64 \\
\hline Tengo confianza con los profesores del instituto & 23.1 & 17.5 & 17.7 & 42.5 \\
\hline $\begin{array}{l}\text { La causa de los problemas de intimidación reside en el clima de } \\
\text { relación que se viva en la familia }\end{array}$ & 26.4 & \multirow{2}{*}{14.2} & \multirow{2}{*}{41.7} \\
\hline $\begin{array}{l}\text { La causa de los problemas de violencia e intimidación reside } \\
\text { en el clima de relación que se viva en el centro educativo }\end{array}$ & 28.8 & \multirow{2}{*}{20.8} & \multirow{2}{*}{30.8} \\
\hline $\begin{array}{l}\text { En el seno de la familia, alguna vez, he tenido que utilizar el daño } \\
\text { físico (pegar) a mi hijo para resolver algún problema de conducta }\end{array}$ & \multirow{2}{*}{39.1} & 14.2 & \multirow{2}{*}{14.6} & \multirow{2}{*}{33} \\
\hline
\end{tabular}

Fuente. Erazo (2013, p. 57).

Los profesores describen que la existencia de la intimidación en su institución es del $35.1 \%$, siendo agredido el $18.4 \%$, y cree que se debe tomar consciencia para actuar el $71.6 \%$, pero el $46.8 \%$ no se siente preparado para abordar el tema, y el $86.3 \%$ considera que es un problema importante pero que no se reflexiona porque la carga laboral no lo permite en el $86.3 \%$.

Los padres consideran que existe intimidación en el colegio en un $31.4 \%$, además creen que su hijo no participaría en estos hechos un $51.9 \%$, pero un $30.3 \%$ considera que sí podría suceder, un $76 \%$ considera que si su hijo fuera víctima se lo contaría, y un $60.3 \%$ confía en que los profesores pueden manejar el tema, pero un $23.1 \%$ no lo considera así. Además creen que la causa de la intimidación es la familia el $59.2 \%$, pero el $51.6 \%$ considera que es el colegio, y en donde para el $47.6 \%$ de los padres es común el castigo físico hacia sus hijos.

\section{Conclusiones}

En la muestra de 1.300 estudiantes de 5 instituciones oficiales del municipio de Popayán, Cauca, Colombia, existe intimidación física, en donde al $38 \%$ le han intentado pegar, al $30 \%$ patear y al $44 \%$ les han quitado sus pertenencias, sucede el hecho más en niños que en niñas. Además el intentar pegar, patear o quitarle cosas a los 9-11 años se da algunas veces entre el $20 \%$ y el $21 \%$ de los $12-14$ años aumenta al $21 \%$ y $28.9 \%$, y de los 15-17 años es del $20.7 \%$, en donde quitar algo le sucede casi al $31.3 \%$, y les sucede bastante entre los 9 a 11 años al $5.8 \%$ y $6 \%$, entre los 12 a 14 años al $6.3 \%$ y $6.8 \%$, y entre los 15 a 17 años al $5.3 \%$ y $7.2 \%$.

Existe intimidación psicológica de diferentes tipos, como decirle apodos al $69.6 \%$, siendo bastante al $11.6 \%$, los gritan al $45.2 \%$, es bastante para el $5.8 \%$, amenazan con darle una paliza al $26 \%$, y bastante al $3.6 \%$, que lo acusaran de forma negativa al $25.3 \%$, siendo bastante al $4.3 \%$, y lo coaccionan para que haga cosas que no desea al $23 \%$, y es bastante al $2.8 \%$ y manipulan la imagen social inventando mentiras al $53.3 \%$, es bastante para el $7.2 \%$, y son desagradables por ser diferente al $32.6 \%$, es bastante para el $7 \%$, y son excluidos por el color de la piel al $24.1 \%$, siendo muy frecuente para el $3.3 \%$.

Respecto a la edad se identifica que la condición no reduce con la edad pero sí la frecuencia del hecho, por ejemplo, poner apodos le sucede algunas veces de los 9-11 años al 34.4\%, y bastante al $11.5 \%$, entre los $12-14$ años algunas veces es casi el $50 \%$, pero bastante el $12.4 \%$ y a los $15-17$ años es algunas veces el $50.3 \%$, y es bastante para el $11.2 \%$, y decir mentiras sobre el estudiante de los 9-11 años es algunas veces casi el $30 \%$, pero bastante es $6.3 \%$, para los 12-14 años algunas veces $36.8 \%$, pero bastante $8.5 \%$, y para los $15-17$ años es algunas veces el $42 \%$, pero bastante al $8.3 \%$, y son groseros por el color de la piel en algunas veces al $9.2 \%$, y bastante el $5.8 \%$, de los $12-14$ años es algunas veces el $9.5 \%$, y es bastante para el $4.6 \%$, y de los $15-17$ es algunas veces el $11.8 \%$, 
y bastante para el $1.7 \%$, y es más frecuente para los hombres.

Además los docentes identifican la intimidación escolar en el $35.1 \%$, pero no está seguro de su existencia el $22.2 \%$, en donde ha sido atacado por el alumnado el $18.4 \%$, y no está seguro el $7.4 \%$. Por su parte el $31.4 \%$ de los padres considera que existe intimidación en el colegio, y no está seguro el $20.6 \%$, y en donde considera que su hijo no estaría involucrado un $52 \%$, pero no está seguro el $30.3 \%$, e indeciso el $17.3 \%$.

Respecto a la intencionalidad y la motivación para intimidar se identifican cuatro factores. Para sentirse fuertes de 9 a 11 años es del $10.5 \%$, en donde el $6.5 \%$ está muy de acuerdo, de los $12-14$ años es del $9.4 \%$, en donde el $5.2 \%$ está muy de acuerdo, de los $15-17$ años es del $16.2 \%$, en donde está muy de acuerdo el $5.6 \%$. Se siente importante cuando demuestra su fuerza de los 9-11 años el $11.6 \%$, de los 12-14 años el $17.9 \%$, estando muy de acuerdo el $8.2 \%$, y entre los 15 a 17 años el $20.1 \%$, estando muy de acuerdo el $9 \%$, y se siente bien agrediendo a otros a la edad de los 9 a 11 años el $5.5 \%$, estando muy de acuerdo el 3.2 \%, de los 12-14 años el $12 \%$, estando muy de acuerdo el $6.6 \%$, y de los 15-17 años el $14 \%$, y está muy de acuerdo el $5.2 \%$.

Lo hace para divertirse poniendo apodos el $19 \%$, estando muy de acuerdo los hombres con el $6.8 \%$ y las mujeres con el $2.2 \%$, y de los 9 a 11 años el $11 \%$, para los $12-14$ años el $16.1 \%$, estando muy de acuerdo el $6.5 \%$, y de los $15-17$ años el $22.4 \%$, estando muy de acuerdo el $13.2 \%$. Piensan que es divertido meterse con los profesores el $9.4 \%$, están muy de acuerdo el $4.4 \%$ de chicos y el $2.2 \%$ de chicas, respecto a su edad entre los 9-11 años el $8 \%$ está de acuerdo, el $6.3 \%$ muy de acuerdo entre los 12 a los 14 años es del $22.4 \%$, están muy de acuerdo el $13.2 \%$ y entre los $15-17$ años es del $14.7 \%$, y están muy de acuerdo el $7.6 \%$.

Se intimida y se utiliza la fuerza para resolver conflictos en el $13.2 \%$ en donde el $5 \%$ está muy de acuerdo y es más frecuente en hombres con el $3 \%$ que en mujeres con el $2 \%$. Además están de acuerdo entre los 9 a 11 años el $9 \%$, y muy de acuerdo el $3.3 \%$, entre los 12 a 14 años es del $13.8 \%$ estando muy de acuerdo el $5.2 \%$, y entre los 15 a 17 años es del $15.2 \%$, estando muy de acuerdo el $5.2 \%$, y se considera que si golpeas tendrás el respeto de otros para el $15.4 \%$, estando muy de acuerdo el $5.8 \%$ de chicos en diferencia de un $2.2 \%$ de chicas en donde a los 9 a 11 años, el $9.1 \%$ está de acuerdo, y muy de acuerdo el $4.5 \%$, de los 12 a 14 años el $16.1 \%$, y entre los 15 a los 17 años el $17 \%$, estando muy de acuerdo el $8.2 \%$. Y controlan a otros con amenazas el $7.9 \%$, en donde están muy de acuerdo los chicos en el $2.1 \%$ y las chicas el $1.4 \%$, de los 9 a 11 años el $5.1 \%$, a los 12 a 14 años el $8.8 \%$, estando muy de acuerdo el $4 \%$, y entre los 15 a 17 años el 7 $\%$, estando muy de acuerdo el $2.9 \%$.

Y se intimida para defenderse en donde las víctimas piensan que es positivo pegarles a los que lo han insultado en un $26.4 \%$, estando muy de acuerdo los chicos con el $9.2 \%$ y las chicas con el $4.8 \%$, en donde los chicos entre 9 a 11 años es del $20.7 \%$, entre los 12 a 14 años es del $26.5 \%$, estando muy de acuerdo el $13.6 \%$, y entre los 15 a los 17 años el $30.1 \%$, en donde es muy de acuerdo el $15.4 \%$, y atacarían para defenderse un $14.6 \%$, estando muy de acuerdo el $3.8 \%$ de chicos y el $2.6 \%$ de chicas entre los 9 a 11 años el $9.6 \%$, de los 12 a 14 años el $19 \%$ y entre los 15 a los 17 años el $19.3 \%$, estando muy de acuerdo el $10.4 \%$.

El $71.6 \%$ de los profesores consideran que es necesario tomar consciencia y actuar, pero necesitan ayuda de profesionales preparados el $46.8 \%$, y en donde el tema en la institución es muy importante para el $86.3 \%$, en donde es difícil su reflexión por falta de tiempo y la carga laboral para el $86.3 \%$.

Además el 58.2 \% considera que la familia y sus relaciones son las causantes del fenómeno, pero un $14.2 \%$ no están seguros y no están de acuerdo el $26.4 \%$, y un $51.6 \%$ considera que el causante es el colegio, aunque están indecisos un $19.4 \%$, y no está de acuerdo con esa afirmación el $28.8 \%$, y corrigen con castigos físicos a sus hijos el $47.6 \%$ de los padres, y no está seguro el $14.2 \%$.

Por lo tanto existe intimidación física en el $38 \%$ y $42 \%$ psicológica, en donde no se conocen sus consecuencias y no se tienen definidos programas de prevención e intervención del fenómeno en estas instituciones. 


\section{Referencias}

Abromovay, M. (2005). Violencia en las escuelas un gran desafío. Revista lberoamericana de Educación, 38, 53-66. Recuperado de http://dialnet. unirioja.es/servlet/articulo?codigo $=1427698$

Álvarez, M. y Rueda, J. (2013). La deserción escolar en la Institución Educativa Jorge Eliécer Gaitán de Robledo, Miramar, ante el desplazamiento de los estudiantes hacia la sede provisional de la Institución la Esperanza, ubicada en el barrio Castilla. Recuperado de http:// bibliotecadigital.usbcali.edu.co/jspui/handle/10819/1580

Aviles, J. (2002). Preconcimei. Cuestionario sobre intimidación y maltrato entre iguales. Valladolid - España. JMAM.

Aviles, J. y Monjas I (2005). Estudio de incidencia de la intimidación y el maltrato entre iguales en la educación secundaria obligatoria mediante el cuestionario CIMEI (Avilés, 1999). Cuestionario sobre intimidación y maltrato entre iguales. Anales de Psicología, 21, 27-41. Recuperado de https://digitum.um.es/jspui/ handle/10201/8045

Aviles, J. (2009). Victimización percibida y bullying. Factores diferenciales entre víctimas. Boletín de Psicología, 95, 7-28. Recuperado de http:// www.uv.es/seoane/boletin/previos/N95-1.pdf

Aviles, J. (2010). Éxito escolar y ciberbullying. Boletín de Psicología, 96, 73-85. Recuperado de http://www.uv.es/seoane/boletin/previos/ N98-5.pdf

Barria, B., Matus C., Yañez M., y Mora R. (2004). Bullying y rendimiento escolar. Trabajo de grado para optar el título de licenciado en Educación. Chile: Universidad Católica de Temuco.

Berkowitz, L. (1996). Agresión: causas, consecuencias y control. Bilbao, España: Editorial Desclee de Brouwer.

Boggon, L. (2006). Violencia, agresividad y agresión: una diferenciación necesaria. Memorias de las XIII jornadas de investigación y segundo encuentro de investigadores en psicología del Mercosur. Paradigmas, métodos y técnicas, tomo II. Editorial: Facultad de Psicología de la Universidad de Buenos Aires. Recuperado de http://newpsi.bvs-psi.org.br/mapa/Argentina/ tomo2.pdf

Bustillo, M. (2014). Una forma de violencia: el acoso escolar. Trabajo de grado para optar al título en educación primaria. Universidad de Valladolid. Recuperado de http://cerro.cpd.uva.es/ bitstream/10324/6864/1/TFG-L696.pdf

Camacho, S. y Ramos, V. (2003, diciembre). Informe final del componente fortalecimiento ciudadano, categorías de inversión jóvenes en riesgo y resocialización, en el proyecto evaluación de productos, efectos e impactos, tempranos surgidos de la ejecución del programa de apoyo a la convivencia y seguridad ciudadana. Informe Técnico AGDT/1096-03. Bogotá, Colombia.

Camargo, M. (1996). Violencia escolar y violencia social. (5 congreso nacional de prevención y atención del maltrato infantil- noviembre 1996). Bogotá: Universidad Nacional. Recuperado de http://www.acosomoral.org/pdf/ rce34_03ensa.pdf

Cerezo, F. (1998). Conductas agresivas en la edad escolar. Madrid, España: Pirámide.

Cerezo, F. (2001). Variables de personalidad asociadas en la dinámica bullying (agresores versus víctimas) en niños y niñas de 10 a 15 años. Revista Anales de Psicología, 17(1), 37-43. Recuperado de https://digitum.um.es/jspui/ handle/10201/7974

Cepeda, C., Pacheco, D., García B., y Piraquive, P. (2008). Acoso escolar a estudiantes de educación básica y media. Revista de Salud Pública, 10, 517-528. Recuperado de http://www.scielo.org.co/pdf/rsap/v10n4/v10n4a02.pdf

Collell, J. y Escude, C. (2004). Rol de las emociones en los procesos de maltrato entre alumnos. Revista Ámbitos de Psicopedagógia, 12, 21-26. Madrid, España. 
Chaux, E. (2003). Agresión reactiva, agresión instrumental y ciclo de la violencia. Revista de Estudios Sociales, 15, 47-58. Recuperado de http://dialnet.unirioja.es/servlet/articulo? codigo $=2349594$

Díaz, M. (2004). Prevención y tratamiento del comportamiento antisocial desde la educación. Trastornos del comportamiento en niños y adolescentes. Madrid, España: Mafre. Recuperado de http://obelen.es/upload/161C.pdf

Defensor del Pueblo. (2007). Violencia escolar: el maltrato entre iguales en la educación secundaria obligatoria, 1999-2006. Madrid, España. Recuperado de http://www.oei.es/oeivirt/Informeviolencia.pdf

Erazo, O. (2012). El intimidador y su intencionalidad: elementos para su comprensión. España: Editorial Académica Española.

Erazo, O. (2013). Identificación y descripción de la intimidación escolar en instituciones oficiales del municipio de Popayán. Trabajo de investigación no publicado. Popayán, Colombia: Fundación Universitaria de Popayán.

Erazo, O. (2013). Caracterización psicológica del estudiante y su rendimiento académico. Revista Colombiana de Ciencias Sociales, 4(1). Recuperado de http://www.funlam.edu.co/ revistas/index.php/RCCS/article/view/948

Erazo, O. (2015). Identificación, características y relación entre la integración sensorial, atención y conducta, problemas en el aula. Trabajo de investigación para optar al título de magíster en Neuropsicología. España: Universidad Internacional de la Rioja.

Estévez, E., Musitu, G., y Herrero, J. (2005). The influence of violent behavior and victimizacion at school on psychological distress: The role of parents and teachers. Adolescence, 40(157), 183-196. Recuperado de https://www.uv.es/ lisis/estevez/estevez_adolescence.pdf

Garnefski, N., y Diekstra, R. (1997). Comorbidity of behavioral, emocional, and congnitive problems in adolescente. Journal of youth and adolescence, 26, 321-338. Recuperado de http://link.springer.com/article/10.1007/ s10964-005-0005-3\#page-1

García, J. (1997). Un modelo cognitivo de las interacciones matón-víctima. Revista Anales de Psicología, 13(1), 51-56. Recuperado de http:// dialnet.unirioja.es/servlet/articulo?codigo $=205291$

Granda, E. (2001). Agresividad y relación entre iguales en el contexto de la enseñanza primaria, estudio piloto. Trabajo de investigación para optar al título de doctor en Cooperación, Desarrollo Social y Democracia. Universidad de Oviedo.

Green, G. (2007). Bullying: A concern for survival. Education, 128, 333-336. Recuperado de http://search.proquest.com/openview/ae092 8ff2743e9ea4d08b0f6c085476a/1?pq-origsite =gscholar

Gálvez-Sobral, A. (2011). El fenómeno del acoso escolar (bullying) en Guatemala. Dirección general de evaluación e investigación educativa. Recuperado de www.mineduc.gob.gt/dige duca

Infante, L., Hierrezuelo, B., García, B., Sánchez, A., de La Morena, M., Muñoz, A. y Trianes, M. (2003). Evaluación de actitudes violentas y clima escolar en situaciones de agresividad en alumnado de secundaria. Psicología, saude y doencas, 4(2). 277-286. Recuperado de http:// www.redalyc.org/pdf/362/36240208.pdf

Jiménez, R. (2005). La delincuencia juvenil. Fenomeno de la sociedad actual. Papeles de población, 43, 215-261. Universidad Autónoma del Estado de México. Recuperado de http:// www.culturadelalegalidad.org.mx/recursos/ Contenidos/Delincuenciajuvenil/documentos/ La\%20delincuencia\%20juvenil,\%20fenomeno\%20de\%20la\%20sociedad\%20actual\%202008. pdf

Llorente, M., Chaux, E. y Salas, L. (2005). De la casa a la guerra: nueva evidencia sobre la violencia 
juvenil en Colombia. Informe final Universidad de Los Andes. Recuperado de http://www. redacademica.edu.co/archivos/redacademi$\mathrm{ca} /$ proyectos/ddhh/autoformacion_ddhh/unidad6/anexo_6-3_informe_uandes.pdf

Mertz, C. (2006). La prevención de la violencia en las escuelas. Programa Paz Educa. Recuperado de http://www.pazciudadana.cl/wp-content/uploads/2013/07/2006-07-03_Laprevenci $\%$ C3\%83\%C2\%B3n-de-la-violencia-en-las-escuelas.pdf

Muñoz, J., Carreras, M. y Braza, P. (2004). Aproximación al estudio de las actitudes y estrategias de pensamiento social y su relación con los comportamientos disruptivos en el aula en la educación secundaria. Revista Anales de Psicología, 20(1). 81-91. Recuperado de http:// www.um.es/analesps/v20/v20_1/08-20_1.pdf http://www.um.es/analesps/v20/v20_1/0820_1.pdf el código de campo es el mismo igual se coloca la correcion.

Moreno, I. (2011). Número monográfico trastornos del comportamiento. Apuntes de psicología, 29(2). 179-182. Recuperado de http://www. apuntesdepsicologia.es/index.php/revista/issue/view/29

Moreno, J. (2006). Comportamiento antisocial en los centros escolares: una visión desde Europa. Revista Cyberpediatria. Recuperado de http:// roble.cnice.mecd.es/ fromero/violencia/intro. htmww.um.es/analesps:1695-2294

Muñoz, G. (2008). Violencia escolar en México y en otros países: comparaciones a partir de los resultados del instituto nacional para la evaluación de la educación. Revista Mexicana de Investigación Educativa, 13(39). Recuperado de http:// www.scielo.org. $\mathrm{mx} / \mathrm{scielo}$.php?pid=\$1405$66662008000400008 \&$ script $=$ sci_arttext\& tlng=pt

Olweus, D. (1994). Annotation: Bullying at school: Basic facts and effects of a school based intervention program. Journal of Child Psychology and Psychiatry, 35(7), 1171-1190. Recuperado de http://onlinelibrary.wiley.com/ doi/10.1111/j.14697610.1994.tb01229.x/abstra ct;jsessionid $=252741 \mathrm{F55CBC} 4 \mathrm{C} 89 \mathrm{D} 9631 \mathrm{AB} 32 \mathrm{~A}$ 3E6234.f01t04?systemMessage $=$ Wiley+Online+ Library+and+related+systems+will+have+3+ho urs+of+downtime+on+Saturday+12th+Septemb er+2015+from +10\%3A00-13\%3A00+BST+\%2F+05\% $3 \mathrm{~A} 0008 \% 3 \mathrm{~A} 00+\mathrm{EDT}+\% 2 \mathrm{~F}+17 \% 3 \mathrm{~A} 0020 \% 3 \mathrm{~A} 00+\mathrm{SGT}$ + for+essential+maintenance.++Apologies + for $+t$ he+inconvenience

Olweus, D. (1998). Conductas de acoso y amenaza entre escolares. Madrid: Morata. Recuperado de https://books.google.com.co/books?hl=es $\notin t r=\& i d=S 0 w S k 71 u Q z 0 C \& o i=f n d \& p g=P A 10 \& d$ $q=$ Olweus, + D.+(1998).+Conductas + de + acoso+ y+amenaza+entre+escolares.+Madrid:+Morat a.\&ots=7zMQgGLxlf\&sig=zUhqE7d1PTIAvvTA Fe1urWA47U\# $\mathrm{v}=$ onepage\& $\mathrm{q}=0$ lweus $\% 2 \mathrm{C} \% 20$ D.\%20(1998).\%20Conductas\%20de\%20acoso\%20 y\%20amenaza\%20entre\%20escolares.\%20 Madrid\%3A\%20Morata.\&f=false

Ortega, R. y Monks, C. (2005). Agresividad injustificada entre preescolares, un estudio preliminar. Revista Psicotema, 17(3), 453-458. Recuperado de http://www.psicothema.com/ psicothema. asp?id=3128

Pautasso, N. (2006). La intimidación entre los niños en edad escolar. Estudio sobre las sutiles prácticas de la violencia en el ámbito de la escuela general básica. Acta académica. Argentina. Recuperado de http://www.aacademica. com/000-039/185

Paredes, M., Álvarez, M., Lega, L., y Vernon, A. (2008). Estudio exploratorio sobre el fenomeno del bullying en la ciudad de Cali, Colombia. Revista Latinoamericana de Ciencias Sociales, Niñez y Juventud, 6(1). Recuperado de http:// www.scielo.org.co/scielo.php?pid=S1692-715X 2008000100010\&script=sci_arttext

Piñuel, I., y Oñate, A. (2007). La violencia y sus manifestaciones silenciosas entre jóvenes: estrategias. Madrid: Instituto de Innovación Educativa y Desarrollo Directivo. Recuperado de http://www.adolescenciasema.org/ficheros/ curso_ado_2009/B-La_violencia_y_sus_manifestaciones_en_jovenes.pdf 
Rodríguez, A. y Celada A. (2005). Caracterización de la violencia escolar en el colegio Sabas Beltrán del corregimiento de Riochiquito municipio de Páez, Cauca. Trabajo de grado para optar al título de especialista en Gerencia de Instituciones Educativas. Ibagué: Universidad del Tolima.

Ruiz, J., Llor, L., Pueblar, T. y Llor, B. (2009). Evaluación de las creencias actitudinales hacia la violencia en centros educativos: el CAHV, 25. European Journal of Education and Psychology, 2(1). 25-35. Recuperado de http://ejep.es/ index.php/journal/article/view/19/pdf_6

Salmivalli, C., Karhunen, J., \& Kirsti M. (1996). How do the victims respond to bullying? Aggressive Behavior, 22, 99-109. Recuperado de http:// www.readcube.com/articles/10.1002\%2F(SICl) 10982337(1996)22\%3A2\%3C99\%3A\%3AAIDAB3\%3E3.0.CO\%3B2P?r3_referer=wol\&tracking _action=preview_click\&show_checkout =1\&purchase_referrer=onlinelibrary.wiley. com\&purchase_site_license=LICENSE_DENIED

Serrano, A. e Iborra I. (2005). Informe violencia entre compañeros en la escuela, Centro Reina Sofía para el Estudio de la Violencia, serie documentos 9. España: Editorial Goaprint, S. L.

Tamar, F. (2005). Maltrato entre escolares (bullying): estrategias de manejo que implementan los profesores al interior del establecimiento escolar. Psyckhe, 14(1), 211-225. Recuperado de http://www.scielo.cl/scielo.php?pid=S071822282005000100016\&script=sci_arttext\&tlng $=e n$
Torres, C. (2005). Jóvenes y violencia. Revista Iberoamericana de Educación, 37, 55-92. Recuperado de http://www.edpcollege.info/ ebooks-pdf/rie37a03.pdf

Torres, M., Orejudo, S., Nasarre, F., Lanuza, R., Madonar, M. y Moreno J. (2006), Conductas de bullying en una muestra rural de secundaria. Informe del departamento de Aragón, España. Recuperado de www.deciencias.net

Ventura, M. (2006). La violencia escolar pega en el mundo contemporáneo. Argentina: Facultad de Psicología, Universidad Nacional de Tucumán.

Vázquez, G., Sarramona, J. y Touriñan, J. (2009). La escuela en crisis. Universidad del Oviedo. Recuperado de http://webspersoais.usc.es/export/sites/default/persoais/josemanuel.tourinan/descargas/ponencia_1_Site_oviedo_pdf. pdf

Zubiría, M. (2006). Matoneo en las aulas. Revista Cambio. Recuperado de http://psicologia. uniandes.edu.co/documentos/echaux/revista\%20cambio\%20matoneo\%20en\%20las\%20aulas.pdf

Zubiría, M., Peralta, D. y Castilla, D. (2009). La violencia escolar entre compañeros en una muestra de colegios privados de Bogotá. Tesis de grado, Instituto Alberto Merani. Recuperado de http://www.institutomerani.edu.co/publicaciones/articulos/2009/articulo_divulgativo_ violencia_escolar_peralta_castilla.pdf 